\title{
INVESTIGATION ON THE MORPHOLOGY AND PROPERTIES OF AGGREGATE STRUCTURES OF NATURAL PHOSPHOLIPIDS IN AQUEOUS SYSTEM USING CRYO-TEM
}

\author{
Dwi Hudiyanti ${ }^{1,2,}$, Tri Joko Raharjo ${ }^{2}$, Narsito $^{2}$, and Sri Noegrohati ${ }^{3}$ \\ ${ }^{1}$ Department of Chemistry, Diponegoro University, Jl. Prof. H. Sudharto, S.H., Tembalang, Semarang, Indonesia 50275 \\ ${ }^{2}$ Department of Chemistry, Faculty of Mathematics and Natural Sciences, Universitas Gadjah Mada, \\ Jl. Sekip Utara, Yogyakarta 55281 \\ ${ }^{3}$ Faculty of Pharmacy, Universitas Gadjah Mada, Yogyakarta, 55281
}

Received November 5, 2011; Accepted January 2, 2012

\begin{abstract}
Cryogenic transmission electron microscopy (Cryo-TEM) was used to investigate the aggregates morphology and properties of candle tree (Aleurites moluccana) endosperm, sesame (Sesamum indicum L. syn.) seeds, and coconut (Cocos nucifera) endosperm phospholipids in dilute aqueous system. The micrographs showed that candle tree phospholipids formed planar bilayer and cluster of vesicles with lipid droplets, while coconut and sesame phospholipids formed well-defined unilamellar vesicles. The vesicles size could be as small as $50 \mathrm{~nm}$ in diameter. Coconut phospholipids also showed a good bending ability. Formation of clusters of vesicles was also found in coconut phospholipids dispersion, but this cluster was easily broken by extrusion through a small pore membrane.
\end{abstract}

Keywords: vesicle; liposome; Cryo-TEM; phospholipids; coconut; sesame seed; candle tree

\section{ABSTRAK}

Mikroskop transmisi elektron kriogenik (Cryogenic transmission electron microscopy, cryo-TEM) digunakan untuk menyelidiki sifat dan morfologi agregat dalam sistem akuos encer dari fosfolipida daging buah kemiri (Aleurites moluccana) dan kelapa (Cocos nucifera) serta biji wijen (Sesamum indicum L. syn.). Mikrograf menunjukkan bahwa fosfolipida kemiri membentuk bilayer planar dan kelompok vesikel dengan tetesan lemak, sedangkan fosfolipida kelapa dan wijen membentuk vesikel unilamellar dengan baik. Diameter ukuran vesikel dapat mencapai $50 \mathrm{~nm}$. Fosfolipida kelapa juga menunjukkan kelenturan yang baik. Pembentukan kelompok vesikel juga ditemukan dalam dispersi fosfolipida kelapa, tapi pengelompokan ini mudah pecah oleh ekstrusi melalui membran berpori kecil.

Kata Kunci: vesikel; liposom; cryo-TEM; fosfolipida; kelapa; wijen; kemiri

\section{INTRODUCTION}

Natural phospholipids can be extracted from various sources, each source gives different unique molecular structures of phospholipids [1-2]. Today the source of phospholipids is mainly soybean and egg yolk. But the demand for and interest in various types of industrial phospholipids are increasing, because of the number of applications for human use also increasing. There is also tendency to replace materials of synthetic origin, with natural products for biocompatibility reasons. This growing demand for natural phospholipids has triggered a search of other sources from natural origin.

In aqueous systems phospholipids aggregate into various dimensional structures, including disks, spherical micelles, planar bilayers and liposomes [3-4]. These 3 dimensional structures determine their uses in industrial applications such as cosmetics, and drugs formulation, and food preparation [5-9]. Thus, knowledge of these aggregate structures of phospholipids from any natural origin is a prerequisite before applying them for industrial purposes.

Important things about aggregate structures are their morphology and properties. Cryo-transmission electron microscopy (Cryo-TEM) offer unique possibilities for investigating the morphology and properties of these structures [10].

In this work we have used Cryo-TEM to investigate the aggregate morphology and properties of candle tree (Aleurites moluccana) endosperm, sesame (Sesamum indicum L. syn.) seeds, and coconut (Cocos nucifera) endosperm phospholipids in a dilute aqueous

* Corresponding author. Tel/Fax : +62-85225064261

Email address : dwi_hudiyanti@undip.ac.id 
system. Hopefully the result would bring into light the prospect of these phospholipids for utilization in industry.

\section{EXPERIMENTAL SECTION}

\section{Materials}

Candle tree (Aleurites moluccana) endosperm, sesame (Sesamum indicum L. syn.) seeds, and coconut (Cocos nucifera) endosperm phospholipids were extracted in house [11]. Concentrated stock solutions were prepared by dissolving the phospholipids in chloroform. PBS solution with $\mathrm{pH}$ 7.4. Phosphate salts and organic solvents of grade 1 were purchased from Merck.

\section{Instrumentation}

The equipments used in this research were Cryotransmission electron microscopy (Cryo-TEM), and Mini Extruder from Avanti Polar Lipids (Alabaster, AL).

\section{Procedure}

\section{Aggregate preparation}

Aggregations of phospholipids were prepared by a procedure adapted from Weesman et al. [12]. It consisted in short of the following. Lipid mixtures were prepared by dissolving the lipids in $\mathrm{CHCl}_{3}$, then removing the solvent under a gentle stream of nitrogen gas and evaporating the remaining $\mathrm{CHCl}_{3}$ in vacuum over night at room temperature. After drying, the lipid films were hydrated in PBS solution.

The lipid mixtures were then subjected to five freeze-thaw cycles, i.e. alternate placement of the suspension-containing vial in liquid nitrogen and in $60^{\circ} \mathrm{C}$ water bath, in each case followed by overtaxing, and then subsequently extruded 30 times through polycarbonate filters of pore size $100 \mathrm{~nm}$ using a Mini Extruder from Avanti Polar Lipids (Alabaster, AL).

\section{Cryo-transmission electron microscopy (Cryo-TEM)}

Specimens for Cryo-TEM examination were prepared in Controlled Environment Vitrification System (CEVS). The system ensures good temperature control and minimizes evaporation during sample preparation.

The technique used for Cryo-TEM examination can be shortly summarized as the following [13]. Thin sample films $(10-500 \mathrm{~nm})$ of the mixed systems were prepared at controlled temperature $\left(25^{\circ} \mathrm{C}\right)$ and relative humidity $(98-99 \%)$ within a custom-built environmental chamber. The films were thereafter vitrified by quick freezing in liquid ethane and transferred to a Zeiss EM 902A transmission electron microscope for examination. Samples were protected against atmospheric conditions, and the temperature was kept below $-165{ }^{\circ} \mathrm{C}$ during both transfer and examination. A zero-energy loss bright-field mode was used, and the accelerating voltage was $80 \mathrm{kV}$. The electron exposures were between 5 and $15 \mathrm{e}-/ \AA 2$, depending on the magnification. The extent of under focus varied approximately between 1 and $2 \mu \mathrm{m}$ and was used to enhance the image contrast. To ensure reproducibility, micrographs presented in the article were chosen from a large number of images.

\section{RESULT AND DISCUSSION}

In order to obtained direct morphology and properties information about the aggregates formed in sample dispersions we investigated the dispersions by Cryo-TEM. All dispersions were prepared in aqueous solution buffered at $\mathrm{pH} 7.4$.

Morphology and properties of phospholipids aggregated structures from candle tree (Aleurites moluccana) endosperm

Interesting structures were observed from the micrographs. Fig. 1 and 2 revealed the formation of planar bilayers and a small number of clusters of aggregated vesicles with lipid droplet (diameter up to $100 \mathrm{~nm}$ ). We also found that droplet of lipids were evidently the dominant particles in the dispersion of candle tree phospholipids.

\section{Morphology and properties of phospholipids aggregated structures from coconut (Cocos nucifera) endosperm}

Fig. 3 shows unilamellar vesicle and clusters of vesicles with size up to $150 \mathrm{~nm}$. Upon extrusion they will be separated into small unilamellar vesicles and small cluster of vesicles (dashed arrows), Fig. 4. The size reduces to less than $100 \mathrm{~nm}$.

It is also important to emphasize that the polydispersity of the vesicles was very high before extrusion. We also found some invaginated and elongated form of vesicles as shown in Fig. 5.

Morphology and properties of phospholipids aggregated structures from sesame (Sesamum indicum L. syn.) seeds

Aggregation of phospholipids from sesame seeds indicates formation of well-defined unilamellar vesicles with diameter up to $50 \mathrm{~nm}$ in the dispersion, as shown in Fig. 6. A few large vesicles (diameter up to $100 \mathrm{~nm}$ ) and small micelles were also detected in the dispersion (micrographs not shown). They were all well separated 


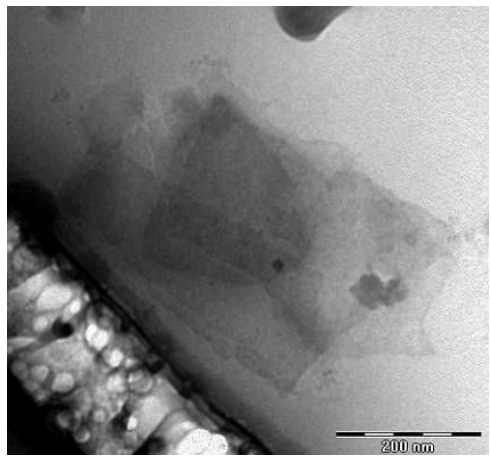

Fig 1. Cryo-TEM image of aggregates from candle tree phospholipids showing formation of planar bilayers

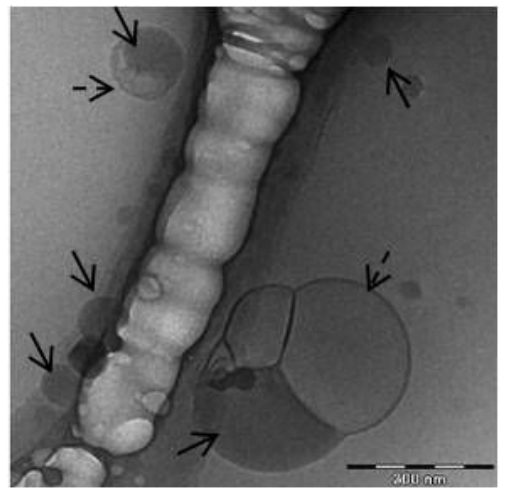

Fig 2. Cryo-TEM image of aggregates from candle tree phospholipids showing clusters of vesicles (straight arrows) with droplet of lipids (dashed arrows)

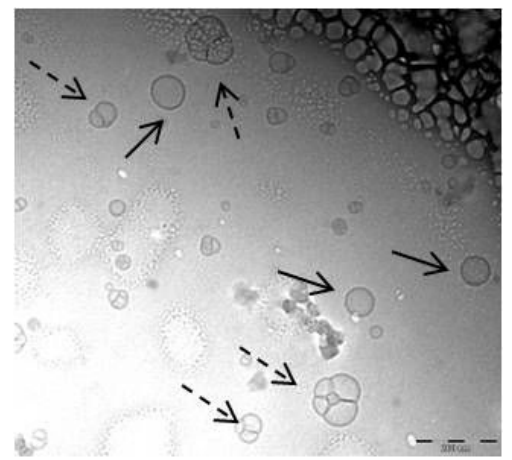

Fig 3. Cryo-TEM image of aggregation of coconut endosperm phospholipids forming single vesicle (straight arrows) and cluster of vesicles (dashed arrows)

from one another.

\section{Morphology and properties of phospholipids aggregated structures from soybean (Glycine max) seeds}

As comparation we also have prepared dispersion from soybean phospholipids. It is known that liposomes

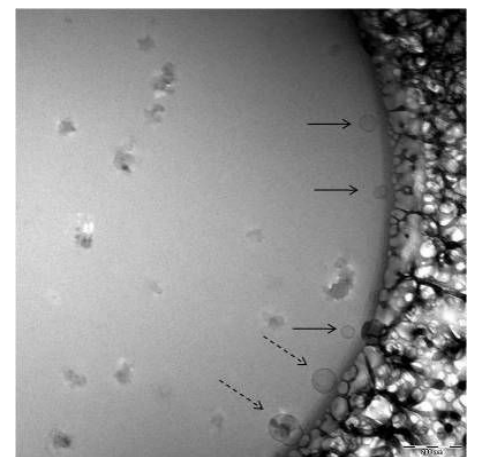

Fig 4. Cryo-TEM image of aggregates from coconut phospholipids forming small unilamellar vesicles (straight arrows) small cluster of aggregated vesicles (dashed arrows)

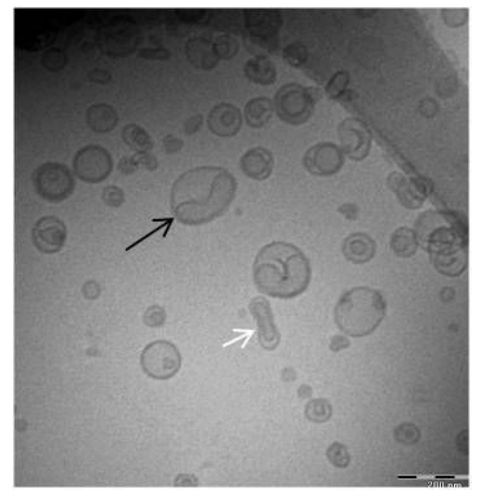

Fig 5. Cryo-TEM image of invaginated (straight arrows) and elongated (white arrows) vesicles

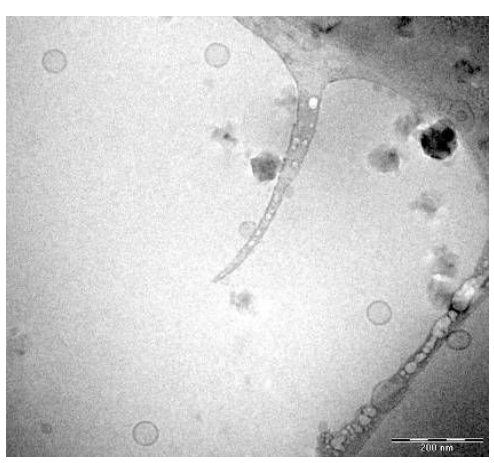

Fig 6. Cryo-TEM image of aggregates from sesame seeds showing formation of well-defined unilamellar vesicles

and other aggregate structures used in industry prepared from soybean phospholipids. The micrograph is presented in Fig. 7 .

The picture indicates formation of well-defined and well-separated unilamellar vesicles with diameter up to $100 \mathrm{~nm}$. 


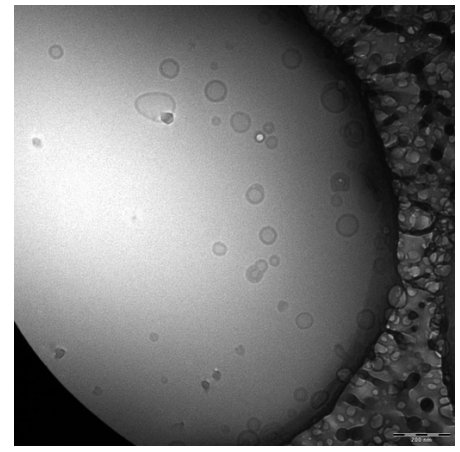

Fig 7. Cryo-TEM image of aggregates from soybean phospholipids showing formation of well-defined unilamellar vesicles

Numerous micrographs for each sample were taken to ensure the validity of results. Interpretation of the samples micrographs was done by comparing them to soybean micrographs.

The results presented above indicate morphological differences in aggregated structures from different origin of the phospholipids. It is likely due to molecular species composing the phospholipids of each sample. Natural sources of phospholipid material contain a number of different classes of phospholipids (molecular species). Different molecular species will pack differently according to theory molecular packing promoted by Israelachvili [14].

The finding in candle tree phospholipids dispersion i.e. planar bilayer and lipid droplets as the dominant materials in the dispersion compare to vesicles suggests that this sample still need further purification and treatment to be useful for industry.

The tendency to invaginate and elongate of coconut phospholipid vesicles is interpreted as a consequence of the softness of the vesicles membrane due to the composition of phospholipid molecular species. Based on the molecular packing theory [14] every phospholipid molecular species have different molecular packing geometry. We think that the molecular species of phospholipid constructing the bilayer membrane consist of mixtures of short-chain and longchain tails and different head group. The molecules arrangement in the membrane building block becomes more irregular compare to if it is only consist of one species molecule. Thus so the molecular interactions, i.e. van der Waals interaction and mostly the hydrophobic effect that keep the membrane intact are distributed unevenly and resulted in the nature of the membrane become more loose, more fluid and softer. The building block is not as compact as it should be. This condition is illustrated in Fig. 8. This leads to lowering of bending rigidity in the event of osmotic gradient occurred between inside and outside membrane. It has been reported that osmotic gradient

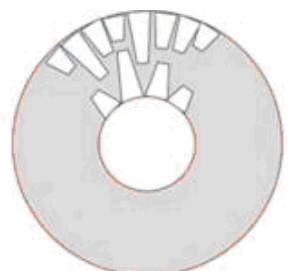

a. loose

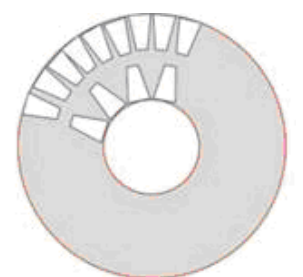

b. compact
Fig 8. illustration of membrane building block, dark area with red outline represents membrane vicinity of vesicle, white parallelogram with blue outline represents phospholipids molecular species. (the illustration does not representing the real size nor ratio of the molecules and vesicles geometry)

may arise from increase of salt concentration outside the membrane due to water evaporation during samples preparation of Cryo-TEM examinations [10]. The result suggests that coconut phospholipids are potentially applicable as vesicle materials for industrial preparation where bending ability is an important aspect to be considered. It should be noted too that coconut vesicle preparation can be as small as $50 \mathrm{~nm}$ in size.

Aggregates from sesame phospholipids show close resemblance to that of soybeans. This finding suggests that, from the morphological point of view, sesame phospholipids have a good potential to be used as alternative substitutes of soybean phospholipids.

Taken together, the results show that phospholipids from coconut endosperm and sesame seeds offer better possibility to be used in industry compare to candle tree. However a lot of work still should be done before actually utilize them for industry. Further studies will be undertaken to investigate other important properties such as the membrane permeability. If the samples demonstrate good permeability, they would provide a number of potential advantages in their utilization.

\section{CONCLUSION}

The Cryo-TEM investigation carried out in this work revealed important information on the aggregate structures forming from candle tree and coconut endosperm, and also sesame seeds phospholipids in dilute aqueous solution. The micrographs showed that candle tree phospholipids form planar bilayer and cluster of vesicles with lipid droplets, while coconut and sesame phospholipids form well-defined vesicles. The vesicles size can be as small as $50 \mathrm{~nm}$ in diameter. Coconut phospholipids also showed a good bending ability. Formations of clusters of vesicles were also found in coconut phospholipids dispersion, but these 
clusters were easily broken by extrusion through a small pore membrane.

\section{ACKNOWLEDGEMENT}

DH would like to express her gratitude to Prof. K. Edwards for fruitful discussion and an opportunity to work in her laboratory, Johny Ericson and Goran Karlson for their help with the Cryo-TEM.

This study was supported in part by Sandwich-Like Program, Directorate General of Higher Education (DGHE) 2009, Ministry of Education and Culture, The Republic of Indonesia.

\section{REFERENCES}

1. Gregor, C., 1993, Phospholipids Handbook, CRC Press, New York, 29-31.

2. Leray, C., 2011, Phosphoglycerides, http://www.cyberlipid.org/phlip/pgly02.htm, accessed on November 11, 2011.

3. Johnsson, M., and Edwards, K., 2003, Biophys. J., 85, 3839-3847.

4. Bergstrand, M., and Edwards, K., 2001, Langmuir, 17, 11, 3245-3253.

5. Fricker, G., Kromp, T., Wendel, A., Blume, A., Zirkel, J., Rebmann, H., Setzer, C., Quinkert, R., Martin, F., and Müller-Goymann, C., 2010, Pharm. Res., 27, 8, 1469-1486.
6. Castor, T.P., 2005, Curr. Drug Deliv., 2, 4, 329340.

7. Nohynek, G.J., Lademann, J., Ribaud, C., and Roberts, M.S., 2007, Crit. Rev. Toxicol., 37, 251277.

8. Patino, J.M.R., Caro, A.L., Nino, M.R.R., Mackie, A.R., Gunning, A.P., and Morris, V.J., 2007, Food Chem., 102, 2, 532-541.

9. Hudiyanti, D., 2007, Aggregasi Fosfolipida dalam Medium Akuos, Proceeding of Seminar Nasional Kimia dan Pendidikan Kimia, Department of Chemistry, Diponegoro University, Semarang, 8590.

10. Almgren, M., Edwards, K., and Karlsson, G., 2000, Colloids Surf., A, 174, 3-21.

11. Hudiyanti, D., Raharjo, T.J., Narsito, and Noegrohati, S., 2008, Isolasi dan Karakterisasi Fosfolipida Nabati, Proceeding of Seminar Nasional Kimia dan Pendidikan Kimia, Department of Chemistry, Sebelas Maret University, Surakarta, 222-226.

12. Weesman, P., Stromstedt, A.A., Malmsten, M., and Edwards, K., 2008, Biophys. J., 95, 9, 4324-4336.

13. Ferreira, D.A., Bentley M.V.L.B., Karlsson, G., and Edwards, K., 2006, Int. J. Pharm., 310, 203-212.

14. Israelachvili, J.N., 1992, Intermolecular and Surface Forces, Academic Press, London, 380382. 